\title{
Extracellular matrix molecules play diverse roles in the growth and guidance of central nervous system axons
}

M.A. Pires-N eto,

S. Braga-de-Souza and R. Lent
Departamento de Anatomia, U niversidade Federal do Rio de Janeiro, Rio de Janeiro, RJ, Brasil

\begin{abstract}
Correspondence
M.A. Pires-Neto

Departamento de Anatomia, UFRJ

21949-590 Rio de Janeiro, RJ

Brasil

E-mail: mapneto@ anato.ufrj.br

Presented at the 5th Brazilian Symposium on Extracellular Matrix - SIMEC, Angra dos Reis,

RJ, Brasil, September 7-10, 1998.

Research supported by Pronex-2 (M inistry of Science and Technology, Brazil).
\end{abstract}

Received December 7, 1998 Accepted January 11, 1999

\section{Abstract}

Axon growth and guidance represent complex biological processes in which probably intervene diverse sets of molecular cues that allow for the appropriate wiring of the central nervous system (CNS). The extracellular matrix (ECM) represents a major contributor of molecular signals either diffusible or membrane-bound that may regulate different stages of neural development. Some of the brain ECM molecules form tridimensional structures (tunnels and boundaries) that appear during time- and space-regulated events, possibly playing relevant roles in the control of axon elongation and pathfinding. This short review focuses mainly on the recognized roles played by proteoglycans, laminin, fibronectin and tenascin in axonal development during ontogenesis.

\section{Key words}

- Axon guidance

- Development

- Anterior commissure

- Corpus callosum

- Brain
The extracellular matrix (ECM) of the embryonic brain is composed of many types of molecules that have distinct patterns of spatial and temporal expression. Many of these components were originally discovered in non-neural tissues and include fibronectin (FN), laminin (LN), vitronectin, collagens, proteoglycans (PGs), tenascin (TN) and thrombospondin $(1,2)$. Their frequent association with developing fiber tracts has given correlative support to the hypothesis that they might be involved in axonal pathfinding, perhaps by establishing boundaries (3) that separate lanes for axon growth and demarcate sites for terminal arborization and synapse formation.

\section{Proteoglycans: diverse signals for growing axons?}

PGs are glycoproteins that exist not only as ECM components, but also as membranespanning, soluble, and intracellular molecules (4). Some of them facilitate or actively pro- mote neurite elongation $(5,6)$. Others have an opposite effect, either inhibiting or providing a nonpermissive substrate for neurite outgrowth (7-9). PGs can also modulate the expression of several cell adhesion molecules, including N-CAM (10), as well as promote the survival of neurons from rat embryonic neocortex (11).

Chondroitin-sulfate proteoglycans (CSPGs) were shown to exist close to radial glial cells that span the reticular nucleus of the thalamus, preceding glial fibrillary acidic protein (GFAP) expression (12). They were also shown to be associated with thalamic axon arborization in the embryonic neocortex (13). Several CSPGs are present in the developing brain, spinal cord and neural crest (14). CSPGs were also observed in association with $\mathrm{LN}$ and $\mathrm{FN}$ in vitro (15), serving as controllers of axonal growth cone velocity. In this context, LN and FN, but neither collagen nor cell adhesion molecules, prevent the inhibitory and repulsive effects of brain CSPGs in a concentration-dependent man- 
ner (16). When expressed in regions containing low levels of adhesion molecules, various CSPGs (phosphacan, neurocan, versican, aggrecan and NG2 proteoglycan) may act as barriers to cell migration and axonal growth, while in regions containing high levels of adhesion proteins, brain CSPGs may still act to maintain certain boundaries while allowing selective axonal extension to proceed (17). There are numerous regions of overlap in the expression patterns of CSPGs and adhesion molecules (6), and the relative levels of these molecules as well as the organization of the extracellular matrix may be important factors that regulate the rate of axonal growth locally. The differential expression of CSPGs, therefore, may be important for modulating axonal growth and guidance during neural development, and their continuous expression may block these events in the normal mature nervous system as well as following brain injury (18).

\section{The tenascin family: controversial roles on axon development}

So far, four members of the TN family (TN-C, -R, -X and -Y) are known (19). The TN family may play many different roles (20), since it displays multiple domains with adhesive and antiadhesive effects. TN has been suggested to bind a neuronal proteoglycan and thus mediate the attachment of glial cells to neurons (21). In the cerebral cortex, TN may not be involved in neuronal migration or axonal growth, since it does not appear until after cortical layers and axonal pathways are established (22). However, in the postnatal cerebellar cortex, $\mathrm{TN}$ is present when parallel fibers are elongating within the molecular layer (23). In the adult cerebral cortical gray matter, TN has been attributed an important inhibitory activity for neurite outgrowth (24). In the mouse, it is present in the optic nerve and in peripheral nerves at the time axons are growing (25). Yet, TN is reported to be absent from both the early limb mesenchyme in regions penetrated by the first axons (26) and from the developing chick optic nerve (27). Further uncertainty about its role comes from in vitro studies that report it can both promote and inhibit neuronal migration and neurite elongation $(1,19,28)$. It is intriguing that animals lacking $\mathrm{TN}$ present no phenotypic abnormality (29), suggesting that TN functions in development are either not essential or not exclusive (30).

\section{Laminin: a permissive substrate for axon growth?}

$\mathrm{LN}$ is known to provide an adhesive substrate to cells, and in particular to provide optimal conditions for neurite outgrowth (31). However, it is clear that $\mathrm{LN}$ isoforms are differentially active in promoting cell adhesion and migration, together with their specific receptors (32). LN supports outgrowth from a wide variety of CNS neurons either alone (33) or associated with heparan sulfate proteoglycan (34). In vivo, some studies have shown punctate LN in various regions, suggesting that it may be important in axon guidance and/ or neuron migration (33). In contrast, some authors suggest that $\mathrm{LN}$ is not related to CNS axon growth (35). Expression of some LN chains in the ependymal layer of the spinal cord has previously been described and has suggested that LN might influence neuronal differentiation and/or axonal projections in the CNS (36). Expression of LN in these cells may provide an important signal to demarcate this region from surrounding tissues and could be related to the fact that the floor plate (or an equivalent prosencephalic region) is considered to be a possible "intermediate target" for commissural axons (32). LN in the developing brain is found along the routes of migrating neuroblasts (33) and also along growing fiber tracts $(37,38)$. It has also been shown at rhombomeric boundaries in the vertebrate hindbrain (39). It is believed that LN is organized differently in the developing and in the adult 
CNS (31). In the former, four different patterns have been described (somatic form, sheath form, small punctiform and large punctiform variants), each associated with different stages of neural development (40).

\section{Fibronectin: diverse roles in axon growth?}

FN is a multifunctional glycoprotein found in the ECM that can mediate cell adhesion, affect cell morphology, migration and differentiation in the CNS, and cause a decrease of growth cone velocity. FN is expressed in embryos and adults, especially in regions of active morphogenesis, cell migration and inflammation, as well as in a wide variety of cells in culture $(41,42)$. In the earliest stages of cortical development, $\mathrm{FN}$ is produced by cells in the ventricular zone throughout the telencephalic vesicle, where it may serve as a component of the local environment that supports cell division and determines cell fate (43). It is also distributed along radial glial processes, being closely associated with preplate neurons, as are chondroitin sulfate proteoglycans and several other ECM components (43). This association continues as preplate cells are divided into the marginal zone and subplate by the invasion of cortical plate neurons, suggesting that ECM, preplate cells and radial glia serve as a scaffold for cortical plate formation (43). FN is also produced by migrating neurons, but only by those moving into specific cortical domains, suggesting that it may help neurons destined for specific targets to discriminate between adjacent glial guides (43). Differently from LN, FN has also been shown to decrease growth cone velocity in vitro (44).

\section{Multimolecular ECM tunnels along the anterior commissure: guiding boundaries for growing axons?}

The development of the anterior commissure (AC) of hamster embryos (Mesocricetus auratus) has been intensely investi- gated along the last decades (45-49).

Recently (50), we have analyzed the immunohistochemical expression of the extracellular matrix molecules CSPG, FN, LN and $\mathrm{TN}$ along the $\mathrm{AC}$ of hamster embryos aged from $\mathrm{E} 12$ to $\mathrm{E} 16(\mathrm{E} 16=\mathrm{P} 1=$ day of birth; $\mathrm{E}=$ embryonic day; $\mathrm{P}=$ postnatal day).

During the precrossing stage (E12-E13), when $\mathrm{AC}$ axons approached the midline region of the brain rostral to the third ventricle, CSPG was expressed as a sagittal stratum between the interhemispheric fissure and the prospective $\mathrm{AC}$ region. $\mathrm{TN}$ appeared rostral to the third ventricle and along the medial subventricular zone of the lateral ventricles. Meanwhile, LN and FN both presented a faint expression. While AC axons started crossing the midline region (crossing stage, E13.5-E14), CSPG, FN, and LN circumscribed the AC bundle (Figure 1) forming a

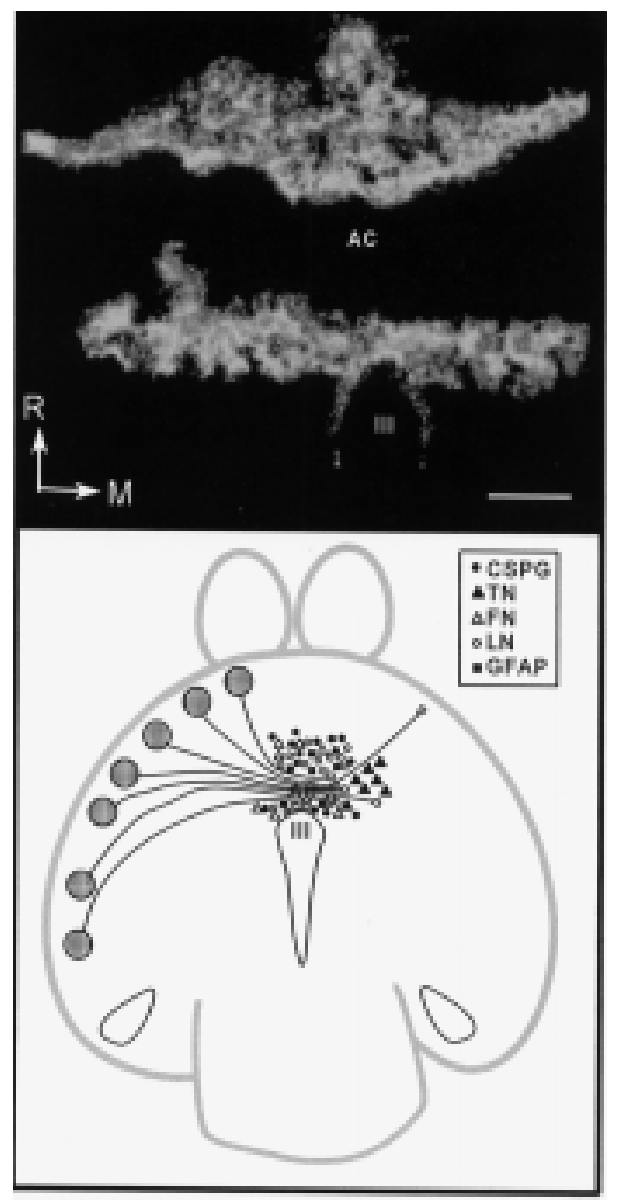

Figure 1 - Top, Horizontal section through an E14 brain rostral to the third ventricle (III) displaying a midline laminin (LN) tunnel that appears while commissural axons cross the anterior commissure (AC) region. Rostral $(R)$ is upwards and medial (M) is to the right. Calibration bar = $150 \mu \mathrm{m}$. Bottom, Schematic representation of molecular expression of chondroitin sulfate proteoglycan (CSPG), tenascin (TN), LN and fibronectin (FN) around the $A C$ bundle during the same developmental stage. GFAP, Glial fibrillary acidic protein. 
Figure 2 - Schematic representation of the molecular tunnel present in the midline region rostral to the third ventricle of the brain. Axons that course along the central portion of the anterior commissure (AC) bundle may advance at a faster rate (pioneer axons), while those at the margins of the tunnel may elongate more slowly (follower axons) due to their closer contact with the molecular components of the tunnel "wall". CSPG, Chondroitin sulfate proteoglycan; LN, laminin; FN, fibronectin.
Figure 3 - Schematic representation of the anterior commissure (AC) branching after crossing the midline region of the brain. Chondroitin sulfate (CS) and tenascin (TN) form boundaries for AC limbs that diverge in order to reach different rostro-caudal targets.
AC Crossing stage (E13.5-E14)

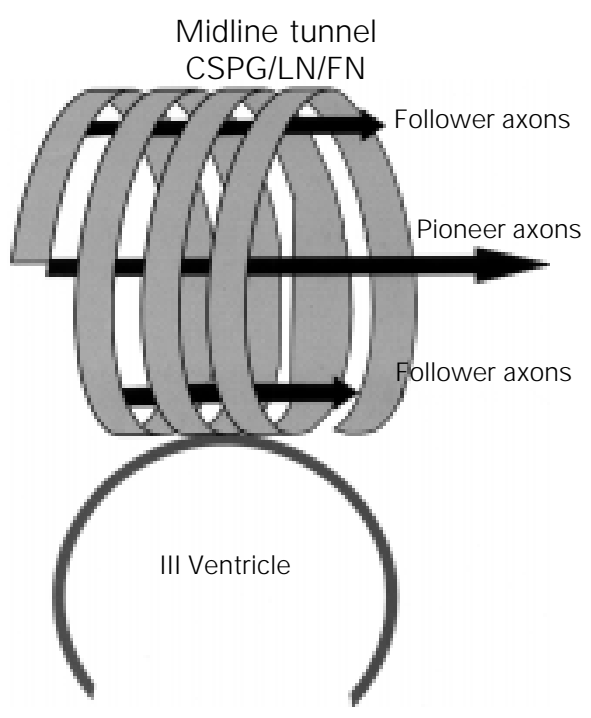

AC Postcrossing stage (E15-E16) Contralateral hemisphere

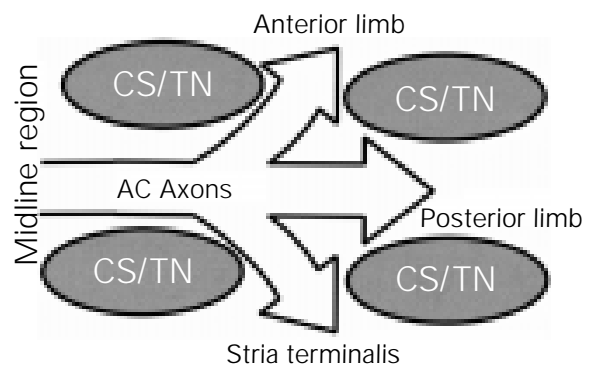

tunnel through which AC fibers elongate. $\mathrm{TN}$ was no longer seen at the midplane, but remained visible laterally.

This midline tunnel has been seen for CSPG in the AC region of other animals (28) and may possibly serve as a convergence attractant for $\mathrm{AC}$ axons towards the crossing region (32), and also serve as influential mechanisms in the deceleration of the marginal axons of the $\mathrm{AC}$ bundle, which would be more exposed to the "wall" of the molecular tunnel, as suggested previously for growing axons in vitro (15). As a consequence, $\mathrm{AC}$ axons advancing through the core of the bundle would be less exposed to these ECM molecules, possibly representing the pioneer axons (Figure 2) observed previously (48).

During the postcrossing stage (E14.5E16), CSPG and TN were no longer seen at the midline, although both could be observed between the AC limbs (Figure 3), seeming to form boundaries for AC lateral growth. $\mathrm{LN}$ and $\mathrm{FN}$ were now absent near the $\mathrm{AC}$ bundle.

We suggest that the expression of extracellular matrix molecules follows a timeand space-regulated course related to $\mathrm{AC}$ development, plausibly representing influential factors for growth and guidance of commissural fibers.

\section{References}

1. Letourneau PC, Condic ML \& Snow DM (1994). Interactions of developing neurons with the extracellular matrix. J ournal of Neuroscience, 14: 915-928.

2. Sheppard AM \& Pearlman AL (1997). Abnormal reorganization of preplate neurons and their associated extracellular matrix: An early manifestation of altered neocortical development in the reeler mutant mouse. J ournal of Comparative Neurology, 378: 173-179.

3. Fitch MT \& Silver J (1997). Glial cell extracellular matrix: boundaries for axon growth in development and regeneration. Cell and Tissue Research, 290: 379-384.

4. Lander AD (1993). Proteoglycans in the nervous system. Current Opinion in Neurobiology, 3: 716-723.

5. Snow DM \& Letourneau PC (1992). Neurite outgrowth on a step gradient of chondroitin sulfate proteoglycan (CS-PG). J ournal of Neurobiology, 23: 322-336.

6. Margolis RU \& Margolis RK (1997). Chondroitin sulfate proteoglycans as mediators of axon growth and pathfinding. Cell and Tissue Research, 290: 343-348.

7. Brittis PA, Canning DR \& Silver J (1992). Chondroitin sulfate as a regulator of neuronal pattern in the retina. Science, 255: 733-736.

8. Snow DM (1994). Neurite outgrowth in response to patterns of chondroitin sul- fate proteoglycan: inhibition and adaptation. Neuroprotocols, 4: 146-157.

9. Dou CL \& Levine J M (1997). Identification of a neuronal cell surface receptor for a growth inhibitory chondroitin sulfate proteoglycan (NG2). J ournal of Neurochemistry, 68: 1021-1030.

10. Grumet $M$, Flaccus $M \&$ Margolis RU (1993). Functional characterization of chondroitin sulfate proteoglycans of brain: interactions with neurons and neural cell adhesion molecules. J ournal of Cell Biology, 120: 815-824.

11. Kappler J , J unghans U, Koops A, Stichel CC, Hausser HJ , Kresse H \& Müller HW (1997). Chondroitin/dermatan sulphate 
promotes the survival of neurons from rat embryonic neocortex. European J ournal of Neuroscience, 9: 306-318.

12. Mitrofanis J , Earle KL \& Reese BE (1997). Glial organization and chondroitin sulfate proteoglycan expression in the developing thalamus. J ournal of Neurocytology, 26: 83-100.

13. Emerling DE \& Lander AD (1996). Inhibitors and promoters of thalamic neuron adhesion and outgrowth in embryonic neocortex: Functional association with chondroitin sulfate. Neuron, 17: 10891100.

14. Margolis RK \& Margolis RU (1993). Nervous tissue proteoglycans. Experientia, 49: 429-446.

15. Snow DM, Brown EM \& Letourneau PC (1996). Growth cone behavior in the presence of soluble chondroitin sulfate proteoglycan (CSPG), compared to behavior on CSPG bound to laminin or fibronectin. International J ournal of Developmental Neuroscience, 14: 331-349.

16. Katoh-Semba R, Matsuda $M$, Kato $K \&$ Oohira A (1995). Chondroitin sulphate proteoglycans in the rat brain: Candidates for axon barriers of sensory neurons and the possible modification by laminin of their actions. European J ournal of Neuroscience, 7: 613-621.

17. Powell EM, Fawcett J W \& Geller HM (1997). Proteoglycans provide neurite guidance at an astrocyte boundary. Molecular and Cellular Neurosciences, 10: 27-42.

18. Grumet M, Friedlander DR \& Sakurai T (1996). Functions of brain chondroitin sulfate proteoglycans during development: Interactions with adhesion molecules. Perspectives in Developmental Neurobiology, 3: 319-330.

19. Faissner A (1997). The tenascin gene family in axon growth and guidance. Cell and Tissue Research, 290: 331-341.

20. Tucker RP (1994). The function of tenascin: hypotheses and current knowledge. Perspectives in Developmental Neurobiology, 2: 1-132.

21. Hoffman S \& Edelman GM (1987). A proteoglycan with HNK-1 antigenic determinants is a neuron-associated ligand for cytotactin. Proceedings of the National Academy of Sciences, USA, 84: 2523-2527.

22. Sheppard AM, Hamilton SK \& Pearlman AL (1991). Changes in the extracellular matrix components accompany early morphogenetic events of mammalian cortical development. J ournal of Neuroscience, 11: 3928-3942.

23. Bartsch S, Bartsch U, Dorries U, Faissner
A, Weller A, Ekblom P \& Schachner M (1992). Expression of tenascin in the developing and adult cerebellar cortex. J ournal of Neuroscience, 12: 736-749.

24. Ghosh A \& David S (1997). Neurite growth inhibitory activity in the adult rat cerebral cortical gray matter. J ournal of Neurobiology, 32: 671-683.

25. Bartsch U, Bartsch S, Dorries U \& Schachner M (1992). Immunohistological localization of tenascin in the developing and lesioned adult mouse optic nerve. European J ournal of Neuroscience, 4: 338352.

26. Wehrle-Haller B, Koch M, Baumgartner S, Spring J \& Chiquet M (1992). Nerve-dependent and -independent tenascin expression in the developing chick limb bud. Development, 112: 627-637.

27. Perez RG \& Halfter W (1993). Tenascin in the developing chick visual system: distribution and potential role as a modulator of retinal axon growth. Developmental Biology, 156: 278-292.

28. Fernaud-Espinosa I, Nieto-Sampedro M \& Bovolenta P (1996). Developmental distribution of glycosaminoglycans in embryonic rat brain: relationship to axonal tract formation. J ournal of Neurobiology, 30: 410-424.

29. Saga $Y$, Yagi T, Ikawa $Y$, Sakakura $T \&$ Aizawa $S$ (1992). Mice develop normally without tenascin. Genes and Development, 6: 1821-1831.

30. Steindler DA, Settles D, Erickson HP, Laywell ED, Yoshiki A, Faissner A \& Kusakabe M (1995). Tenascin knockout mice: Barrels, boundary molecules and glial scars. J ournal of Neuroscience, 15: 1971-1983.

31. Luckenbill-Edds L (1997). Laminin and the mechanism of neuronal outgrowth. Brain Research Reviews, 23: 1-27.

32. Lentz SI, Miner J H, Sanes J R \& Snider WD (1997). Distribution of the ten known laminin chains in the pathways and targets of developing sensory axons. J ournal of Comparative Neurology, 378: 547561.

33. Hunter DD, Llinás R, Ard M, Merlie J P \& Sanes J (1992). Expression of S-laminin and laminin in the developing rat central nervous system. J ournal of Comparative Neurology, 323: 238-251.

34. Dow KE \& Riopelle RJ (1994). Modulation of neurite promoting proteoglycans by neuronal differentiation. Developmental Brain Research, 80: 175-182.

35. Gordon-Weeks PR, Golding J P, Clarke J D $\&$ Tonge D (1992). A study of the expression of laminin in the spinal cord of the frog during development and regeneration. Experimental Physiology, 77: 681692.

36. Thomas T \& Dziadek M (1993). Genes encoding for basement membrane glycoproteins, laminin, nidogen, and collagen IV are differentially expressed in the nervous system and by epithelial, endothelial, and mesenchymal cells of the mouse embryo. Experimental Cell Research, 208: 54-67.

37. Letourneau PC, Pech IV, Rogers SL, Palms SL, McCarthy J B \& Furcht LT (1988). Growth cone migration across extracellular matrix components depends on integrin but migration across glioma cells does not. J ournal of Neuroscience Research, 21: 286-297.

38. Liesi P, Hager G, Dodt HU, Seppala I \& Zieglgansberger W (1995). Domain-specific antibodies against the B2 chain of laminin inhibit neuronal migration in the neonatal rat cerebellum. J ournal of Neuroscience Research, 40: 199-206.

39. Wilson SW, Placzek M \& Furley A (1993). Border disputes: do boundaries play a role in growth-cone guidance? Trends in Neuroscience, 16: 316-322.

40. Zhou FC (1990). Four pattems of lamininimmunoreactive structure in developing rat brain. Developmental Brain Research, 55: 191-201.

41. Stewart GR \& Pearlman AL (1987). Fibronectin-like immunoreactivity in the developing cerebral cortex. J ournal of Neuroscience, 7: 3325-3333.

42. Chun J J M \& Shatz CJ (1988). A fibronectin-like molecule is present in the developing cat cerebral cortex and is correlated with subplate neurons. J ournal of Cell Biology, 106: 857-872.

43. Pearlman AL \& Sheppard AM (1996). Extracellular matrix in early cortical development. Progress in Brain Research, 108: 117-134.

44. Kuhn TB, Schmidt MF \& Kater SB (1995). Laminin and fibronectin guideposts signal sustained but opposite effects to passing growth cones. Neuron, 14: 275-285.

45. Silver J, Lorenz SE, Wahlsten D \& Coughlin J (1982). Axonal guidance during development of the great cerebral commissures: Descriptive and experimental studies in vivo on the role of preformed glial pathways. Joumal of Comparative Neurology, 210: 10-29.

46. Lent R \& Guimarães RZ (1991). Development of paleocortical projections through the anterior commissure of hamsters adopts progressive, not regressive, strategies. J oumal of Neurobiology, 22: 475-498. 
47. Pires-Neto MA \& Lent R (1991). Pioneer axons in the anterior commissure of hamster embryos. Brazilian J ournal of Medical and Biological Research, 24: 1067-1070.

48. Pires-Neto MA \& Lent R (1993). The prenatal development of the anterior commissure in hamsters: Pioneer fibers lead the way. Developmental Brain Research, 72: 59-66.

49. Pires-Neto MA, Lent R \& Hartmann ALC (1994). Topographic organization in the anterior commissure of developing hamsters. Brazilian J ournal of Medical and Biological Research, 27: 1369-1376.
50. Pires-Neto MA, Braga-de-Souza $S \&$ Lent R (1998). Molecular tunnels and boundaries for growing axons in the anterior commissure of hamster embryos. J oumal of Comparative Neurology, 399: 176-188. 